\title{
Comparison of the Effects of Sufentanil and Fentanyl Intravenous Patient Controlled Analgesia after Lumbar Fusion
}

Do Keun Kim, M.D., ${ }^{1}$ Seung Hwan Yoon, M.D., Ph.D., ${ }^{1}$ Ji Yong Kim, M.D., ${ }^{2}$ Chang Hyun Oh, M.D., Ph.D., ${ }^{3}$ Jong Kwon Jung, M.D., Jin Kim, M.D. ${ }^{4}$

Department of Neurosurgery, Inha University Hospital, Incheon, Korea

Department of Neurosurgery, ${ }^{2} \mathrm{Na}$-Eun Hospital, Incheon, Korea

Department of Neurosurgery, ${ }^{3}$ Guro Cham TeunTeun Hospital, Seoul, Korea

Department of Anesthesiology, ${ }^{4}$ Inha university Hospital, Incheon, Korea

Objective : Postoperative pain is one of the major complaints of patients after lumbar fusion surgery. The authors evaluated the effects of intravenous patient controlled analgesia (IV-PCA) using fentanyl or sufentanil on postoperative pain management and pain-related complications.

Methods : Forty-two patients that had undergone surgery with lumbar instrumentation and fusion at single or double levels constituted the study cohort. Patients were equally and randomly allocated to a sufentanil group (group S) or a fentanyl group (group F) for patient controlled analgesia (PCA). Group S received sufentanil at a dose of $4 \mu \mathrm{g} / \mathrm{kg}$ IV-PCA and group F received fentanyl 24 $\mu \mathrm{g} / \mathrm{kg}$ IV-PCA. A numeric rating scale (NRS) of postoperative pain was applied before surgery, and immediately and at 1, 6, and 24 hours (hrs) after surgery. Oswestry disability index (ODI) scores were obtained before surgery and one month after surgery. Opioidrelated side effects were also evaluated.

Results : No significant intergroup difference was observed in NRS or ODI scores at any of the above-mentioned time points. Side effects were more frequent in group F. More specifically, nausea, vomiting rates were significantly higher $(p=0.04)$, but pruritus, hypotension, and headache rates were non-significantly different in the two groups.

Conclusion : Sufentanil displayed no analgesic advantage over fentanyl postoperatively. However, sufentanil should be considerable for patients at high risk of $\mathrm{Gl}$ issues, because it had lower postoperative nausea and vomiting rates than fentanyl.

Key Words : Postoperative pain · Lumbar fusion · Sufentanil · Fentanyl · IV-PCA.

\section{INTRODUCTION}

Intravenous patient controlled analgesia (IV-PCA) is a commonly used straightforward and effective method of pain control after surgery ${ }^{4,5,8,18}$. Fentanyl is a potent synthetic opioid analgesic with a rapid onset and short duration of action, and is a strong agonist of $\mu$-opioid receptors. Fentanyl is 80 to 100 times more potency than morphine and 40 to 50

- Received: July 19, 2016 •Revised: September 19, 2016 •Accepted: September 22, 2016

- Address for reprints : Seung Hwan Yoon, M.D., Ph.D.

Department of Neurosurgery, Inha University Hospital, 27 Inhang-ro, Jung-gu, Incheon 22332, Korea

Tel : +82-32-890-2619, Fax : +82-32-890-2374, E-mail : nsyoon@gmail.com

This is an Open Access article distributed under the terms of the Creative Commons Attribution Non-Commercial License (http://creativecommons.org/licenses/by-nc/4.0) which permits unrestricted non-commercial use, distribution, and reproduction in any medium, provided the original work is properly cited. 
times more potent than pharmaceutical grade heroin. However, despite its excellent analgesic effect, nausea and vomiting caused by high dosages prevents its clinical usage in some patients. On the other hand, sufentanil is 5 to 10 times more potent than its parent fentanyl, and thus, smaller dosages are required to relieve pain ${ }^{12)}$. In addition, fentanyl provides high quality analgesia during the immediate postoperative period.

It has been well demonstrated that fentanyl and sufentanil based PCA significantly reduces pain score versus controls $^{4,5,13,15)}$. However, no previous study has compared the analgesic and side effects of these two drugs.

This double blind-randomized control study was conducted in patients that underwent lumbar fusion surgery to compare fentanyl and sufentanil based IV-PCA with respect to pain relief and side effects.

\section{MATERIALS AND METHODS}

This randomized, double-blind control-trial study was approved by the ethics committee for human research at Inha university hospital. Forty-two patients aged from 30 to 70 years that underwent lumbar fusion at one or two levels in an university hospital from October 2014 to July 2015 were enrolled in the study. At time of enrollment all patients were of American Society of Anesthesiologists status (ASA) I-III and scheduled to undergo elective lumbar fusion surgery due to degenerative spinal disease. Patients with a history of drug allergy or psychiatric disease, or with an acute traumatic fracture, infection, tumor, previous history of malignancy, or bleeding tendency were excluded. In addition, patients with postoperative complications that increased postoperative pain with pain evaluations deemed unreliable because of neurologic disease were excluded. All operations were performed by one neurosurgeon (JYK).

The 42 patients were randomly allocated to two groups, that is, a fentanyl group (group F; $\mathrm{n}=21$ ) or a sufentanil group (group S; $\mathrm{n}=21$ ), using random-maker software (R-console; $\mathrm{R}$ foundation for statistical computing 2014). Patients in group F received IV-PCA with fentanyl $(24 \mu \mathrm{g} / \mathrm{kg})$ mixed with nor- mal saline to a total volume of $60 \mathrm{~mL}$, whereas patients in group S received IV-PCA sufentanil $(4 \mu \mathrm{g} / \mathrm{kg})$ mixed with normal saline also to a total volume of $60 \mathrm{~mL}$. One observer was responsible for the group allocations, and the operator and anesthesiologist were unaware of group allocations.

All patients underwent lumbar pedicle screw insertion with or without interbody fusion at 1 or 2 levels. The numeric rating scale (NRS) for pain was applied before surgery, and then immediately and at 1, 6, and 24 hrs after surgery. The Oswestry disability index (ODI) was applied preoperatively and at 1 month after surgery. NRS scores were rated using a 10-point scale, as follows, low pain 1-3, moderate pain 4-7, and severe pain 8-10. Numbers of patients in these categories were compared.

Groups $\mathrm{S}$ and $\mathrm{F}$ were compared with respect to side effects associated with IV-PCA, that is nausea, vomiting, pruritus, headache, hypotension, sedation, and respiratory depression. Demographic and clinical parameters, which included age, sex, height, weight, number of operation levels, duration of IV-PCA, and operation time were assessed. The primary outcome was severity of postoperative pain and side effects were viewed as secondary outcomes.

Data was collected and analyzed using SPSS version 14.0 for Windows (SPSS Inc., Chicago, IL, USA). Results are presented as means \pm standard deviation (SDs). The independent sample $t$-test, the Chi-square test, or the Mann-Whitney $U$ test were used to group variables. Statistical significance was accepted for $p$ values $<0.05$.

\section{RESULTS}

Group characteristics and clinical parameters are summarized in Table 1. Demographic data, including, mean age, gender, height, weights, operation levels, duration of IV-PCA, and operation time were no different in group $\mathrm{F}$ and $\mathrm{S}$.

A comparison of group NRS scores showed that before surgery, immediate after surgery, and at 1, 6, and $24 \mathrm{hrs}$ after surgery median pain scores were similar (Table 2, Fig. 1). Mean preoperative ODI scores in groups F and S were 22.4 \pm 
Table 1. Baseline characteristics and clinical parameters of the two study groups

\begin{tabular}{lccc}
\hline Variables & $\begin{array}{c}\text { Group F } \\
(\mathbf{n}=\mathbf{2 1})\end{array}$ & $\begin{array}{c}\text { Group S } \\
(\mathbf{n = 2 1 )}\end{array}$ & $\boldsymbol{p}$-value \\
\hline Age (yrs) & $61.3 \pm 10.5$ & $62.8 \pm 9.9$ & $0.63^{*}$ \\
Sex: M & $6(28.5)$ & $11(52.4)$ & $0.61^{\dagger}$ \\
Sex: F & $15(71.5)$ & $10(47.6)$ & \\
Height (cm) & $158.2 \pm 8.6$ & $161.71 \pm 7.8$ & $0.09^{*}$ \\
\hline Weight (kg) & $60.6 \pm 9.7$ & $65.7 \pm 9.0$ & $0.18^{*}$ \\
OP level 1 & $18(85.7)$ & $16(76.2)$ & $0.72^{\dagger}$ \\
OP level 2 & $3(14.3)$ & $5(23.8)$ & \\
Duration of PCA (hrs) & 86.64 & 80.32 & $0.90^{*}$ \\
\hline OP time (min) & $173.3 \pm 34.7$ & $176.2 \pm 46.8$ & $0.86^{*}$ \\
\hline
\end{tabular}

Values are presented as mean \pm standard deviation or number (\%). Statistical analysis was performed using the ${ }^{*}$ Independent sample $t$-test or the ${ }^{\dagger}$ Chi-square test. PCA : patient controlled analgesia

Table 2. NRS scores of the two groups at different times

\begin{tabular}{lccc}
\hline NRS & Group $\mathbf{F}(\mathbf{n}=\mathbf{2 1})$ & Group $\mathbf{S}(\mathbf{n}=\mathbf{2 1})$ & $\boldsymbol{p}$-value \\
\hline PreOP & $7.0 \pm 1.6$ & $7.4 \pm 1.4$ & 0.32 \\
PostOP & $7.0 \pm 1.5$ & $7.3 \pm 1.3$ & 0.41 \\
After $1 \mathrm{hr}$ & $5.3 \pm 1.7$ & $5.4 \pm 1.7$ & 0.84 \\
After $6 \mathrm{hr}$ & $3.8 \pm 2.1$ & $3.8 \pm 3.6$ & 0.69 \\
After $24 \mathrm{hr}$ & $2.8 \pm 1.4$ & $3.1 \pm 1.2$ & 0.21 \\
\hline
\end{tabular}

Values are presented as mean \pm standard deviation. $p$-values were calculated using the Mann-Whitney test. NRS : numeric rating scale

Table 3. ODI scores of the two groups

\begin{tabular}{lccc}
\hline ODI & Group $\mathrm{F}(\mathbf{n}=\mathbf{2 1})$ & Group $\mathbf{S}(\mathbf{n}=\mathbf{2 1})$ & $\boldsymbol{p}$-value \\
\hline PreOP & $22.4 \pm 8.9$ & $24.0 \pm 7.0$ & 0.53 \\
1 month after & $12.5 \pm 7.9$ & $14.0 \pm 7.6$ & 0.55 \\
\hline
\end{tabular}

Values are presented as mean \pm standard deviation. ODI : Oswestry disability index

8.9 and $24.0 \pm 7.0$, resp. At one month postoperatively these decreased to $12.5 \pm 7.9$ and $14.0 \pm 7.6$, respectively, which was not a significant difference (Table 3, Fig. 2).

Frequencies of pain severities after surgery in the two groups are summarized in Table 4 and Fig. 3. The majority of patients in both groups had severe pain immediately after surgery, but most had only low pain at 24 hours after surgery. Pain severities reduced with time in both groups, and no intergroup difference was observed at any time point $(p>0.05)$.

Ten of the 21 patients in group $F$ and 6 of the 21 patients in group $S$ exhibited an adverse effect related to opioid $(p=0.21)$.

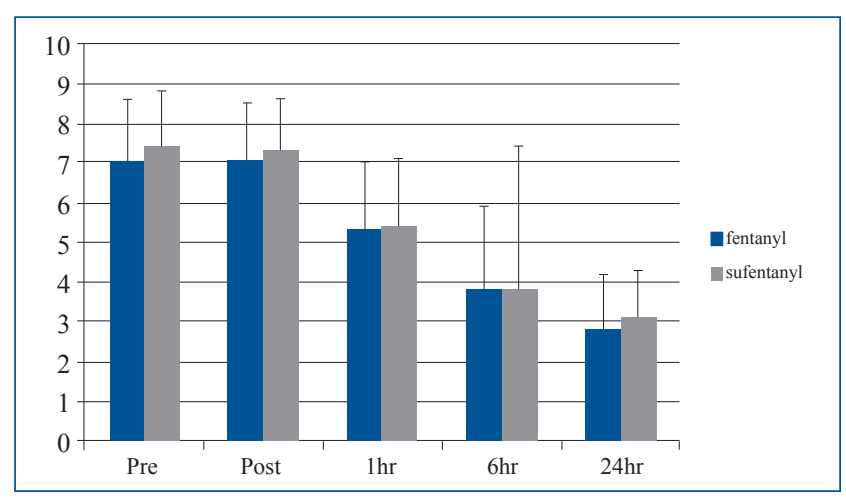

Fig. 1. NRS scores in the two study groups. NRS: numeric rating scale.

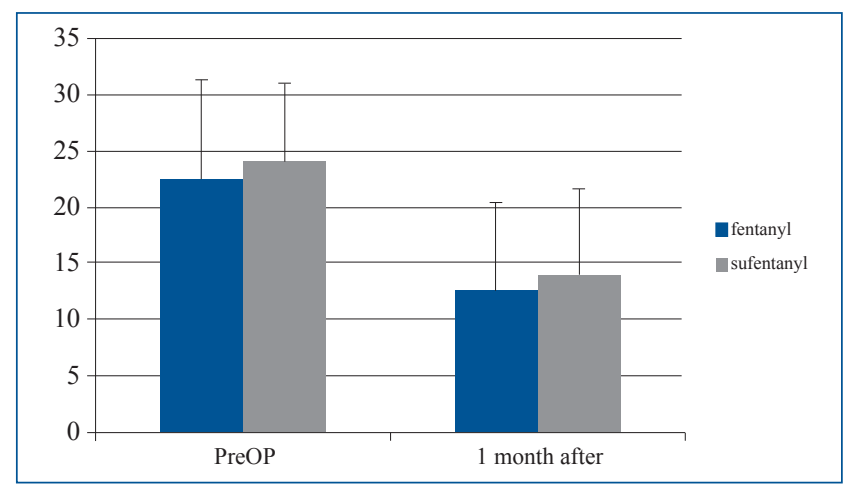

Fig. 2. Group ODI scores. ODI : Oswestry disability index.

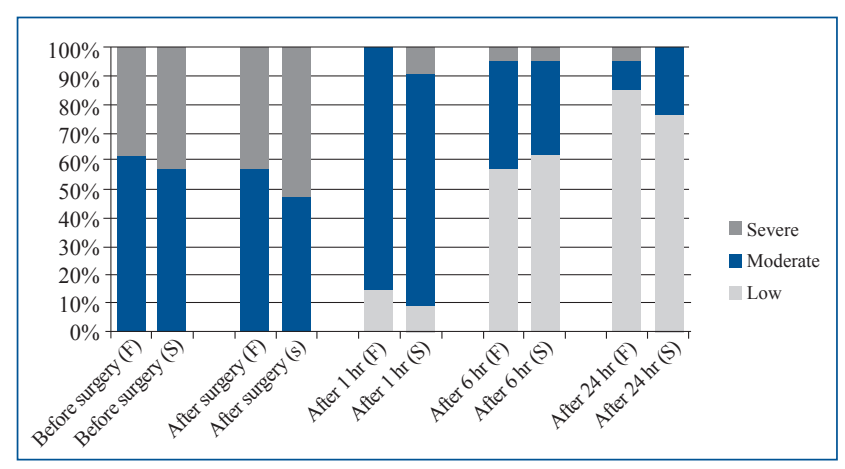

Fig. 3. Frequencies of NRS assessed pain severities after surgery in the study groups. NRS: numeric rating scale.

Nausea and vomiting were the most common adverse effects in both groups. Six patients were affected in group F and 1 patient in group $\mathrm{S}$. $(p=0.04)$ Two patients in group $\mathrm{F}$ and 3 in group $S$ showed pruritus after IV-PCA ( $p=0.64)$, and one patient in each group developed a headache and hypotension. No patient exhibited sedation or respiratory depression (Table 5). 
Table 4. Frequencies of different pain severities of pain after surgery in the two groups

\begin{tabular}{|c|c|c|c|c|c|c|c|}
\hline \multirow{2}{*}{ NRS } & \multicolumn{3}{|c|}{ Group F $(n=21)$} & \multicolumn{3}{|c|}{ Group $S(n=21)$} & \multirow{2}{*}{$p$-value } \\
\hline & Low & Moderate & Severe & Low & Moderate & Severe & \\
\hline Before surgery & 0 & 13 & 8 & 0 & 12 & 9 & 0.76 \\
\hline After surgery & 0 & 12 & 9 & 0 & 10 & 11 & 0.36 \\
\hline After $1 \mathrm{hr}$ & 3 & 18 & 0 & 2 & 17 & 2 & 0.27 \\
\hline After $6 \mathrm{hr}$ & 12 & 8 & 1 & 13 & 7 & 1 & 0.87 \\
\hline After $24 \mathrm{hr}$ & 18 & 2 & 1 & 16 & 5 & 0 & 0.31 \\
\hline
\end{tabular}

$p$-values were calculated using the Mann-Whitney test. NRS : numeric rating scale

Table 5. The incidences of adverse effect in the two groups

\begin{tabular}{lccc}
\hline Adverse effect & Group F (n=21) & Group S (n=21) & p-value \\
\hline Nausea/vomiting & $6(28.6)$ & $1(4.8)$ & 0.04 \\
Pruritis & $2(9.5)$ & $3(14.3)$ & 0.64 \\
Headache & $1(4.8)$ & $1(4.8)$ & - \\
Hypotension & $1(4.8)$ & $1(4.8)$ & - \\
Sedation & 0 & 0 & - \\
Respiration depression & 0 & 0 & - \\
\hline
\end{tabular}

Values are presented as number (\%). $p$-values were calculated using the Mann-Whitney test

\section{DISCUSSION}

Lumbar fusion surgery is one of the most commonly performed spinal surgical procedures, especially in the elderly. Treatment success rates are high, but postoperative pain is common and severe. Most patients suffer severe pain at rest during the first 12 hrs after surgery, and at $48-72$ hrs after surgery pain eases when resting, but remains severe during movement ${ }^{1}$. Despite the benefits of lumbar fusion surgery, immediate postoperative pain is one of the common complaint, and after lumbar fusion surgery patients may experience severe postoperative pain if analgesia is not managed appropriately ${ }^{20)}$. Some previous studies have shown less postoperative pain is associated with a lower risk of developing chronic pain, shorter hospital stays, faster recoveries, better patient and physician satisfaction, better cardiac, respiratory, and gastrointestinal functions, and lower incidences of thromboembolic complications ${ }^{10,19)}$.

Although operator skill and successful fusion rates are important, postoperative pain control should not be overlooked by surgeons. Appropriate postoperative pain management is essential for early ambulation, reduced hospital stay, avoidance of additional analgesics, and for improving patient outcomes ${ }^{13)}$. In particular, in elderly patients, postoperative pain can provoke respiratory and cardiovascular complications, and thus, careful pain management is critical. IV-PCA is one of the best modalities for controlling postoperative pain after lumbar fusion for two reasons. First, IV-PCA needs no additional procedure for pain control ${ }^{2,5,13,22)}$. Second, both fentanyl and sufentanil, which are highly lipophilic opioids, are rapidly absorbed into the blood stream so it show very rarely procedure related neurologic deficits immediately after surgery $^{2,5,11,13,21)}$.

Sufentanil is an opioid that stands apart from other opioids because of its rapid onset and analgesic potency, for example, as compared to fentanyl, intravenous sufentanil is $5-10$ times more potent ${ }^{17,24)}$, and in the extradural space $3-5$ times more potent ${ }^{14,17)}$. This efficacy is mainly due to its high lipid solubility and ability to cross the blood-brain barrier. In fact, sufentanil is a more powerful analgesic than any other clinical used opioids.

While planning this study, we expected sufentanil would provide powerful pain relief due to its pharmacologic poten$c y$, but no significant difference was observed between group NRS scores before surgery ( $p=0.32$ ), immediately after surgery $(p=0.41)$, or at $1(p=0.84), 6(p=0.69)$, or 24 hours after surgery $(p=0.21)$. In fact, both fentanyl and sufentanil IVPCA provided satisfactorily postoperative pain relief. IVPCA is one of the most frequently used means of providing pain relief after short-stay elective surgeries. In such patients, postoperative pain is experienced episodically immediately after surgery and decreases after 24 hours ${ }^{7}$. 
Like other opioids, sufentanil induces characteristic opioid side effects, although types and severities of side effects differ. Some studies have reported sufentanil has a lower tendency than fentanyl to induce nausea and vomiting ${ }^{9,12,17,23)}$. whereas other have reported it has a greater tendency ${ }^{6,16)}$. In the present study, nausea and vomiting was the most frequent side effect or their opioid; 6 patients (28.6\%) in both group $\mathrm{F}$ and one patient $(4.8 \%)$ in group $\mathrm{S}$, and this represented a significant difference $(p=0.04)$. Pruritus is also a commonly described complication of sufentanil, and in the present study, 2 patients (9.5\%) in group $\mathrm{F}$ and 3 patients (14.3\%) in group $S$ had pruritus ( $p=0.64)$. Nevertheless, in all affected patients, pruritus rapidly disappeared after an antihistamine injection. Furthermore, the incidence of pruritus was not high, which was expected because it is normally encountered after a central block, rarely after general administration. Despite the sufentanil induced release of histamine from basophils, the nature of post-opioid pruritus does not appear to be directly related to this phenomenon; naloxone has been reported to cause the gradual subsidence of postopioid pruritus, but at a much slower rate than other side effects ${ }^{3,14,17)}$. Previous comparative studies on the incidence of pruritus after fentanyl or sufentanil via IV or epidural PCA found no significant difference between the two drugs ${ }^{6,9,16,23)}$. Headache and hypotension occurred in 1 case each in their study groups (4.8\%). Bradycardia is a commonly addressed complication associated with a single dose of sufentanil, but it is usually caused rapid administration. No case of bradycardia, sedation, or respiratory distress was observed in the present study.

The low sample size of the present study is an obvious limitation. However, the study was powered sufficiently to assess meaningfully differences in primary outcome measures, but on the other hand the low sample size meant that our analysis of secondary outcome measures (nausea and vomiting, hypotension, and pruritus) was at significant risk of type II errors. Therefore, we recommend larger-scale multicenter studies be conducted to assess pain scores and to determine the incidences of nausea and vomiting, hypotension and pruritus in patients on IV-PCA after lumbar fusion surgery.

\section{CONCLUSION}

In summary, our findings reveal that fentanyl and sufentanil IV-PCA after lumbar fusion surgery were not significantly different in terms of postoperative pain control; if fact both successfully achieved pain control. Nausea and vomiting were less frequent in the sufentanil group, and sufentanil at only $17 \%$ of the dosage of fentanyl achieved the same analgesic effect with fewer complications. The study suggests sufentanil be considered a valid alternative to fentanyl for postoperative pain control in patients with GI issues.

\section{- Acknowlegments}

This work was supported by Inha University Hospital Research Grant.

\section{References}

1. Bianconi M, Ferraro L, Ricci R, Zanoli G, Antonelli T, Giulia B, et al. : The pharmacokinetics and efficacy of ropivacaine continuous wound instillation after spine fusion surgery. Anesth Analg 98 : 166-172, 2004

2. Bost P, Commun F, Albuisson E, Guichard C, Mom T, Eschalier A, et al. : Postoperative pain assessment in head and neck cancer surgery: benefit of patient controlled analgesia (PCA). Ann Otolaryngol Chir Cervicofac 116 : 154-161, 1999

3. Brownstein MJ : A brief history of opiates, opioid peptides, and opioid receptors. Proc Natl Acad Sci USA 90 : 5391-5393, 1993

4. Cata JP, Noguera EM, Parke E, Ebrahim Z, Kurz A, Kalfas I, et al. : Patientcontrolled epidural analgesia (PCEA) for postoperative pain control after lumbar spine surgery. J Neurosurg Anesthesiol 20 : 256-260, 2008

5. Cohen BE, Hartman MB, Wade JT, Miller JS, Gilbert R, Chapman TM : Postoperative pain control after lumbar spine fusion. Patient-controlled analgesia versus continuous epidural analgesia. Spine (Phila Pa 1976) 22 : 1892-1896; discussion 1896-1897, 1997

6. Cohen S, Amar D, Pantuck CB, Pantuck EJ, Goodman EJ, Widroff JS, et al. : Postcesarean delivery epidural patient-controlled analgesia. Fentanyl or sufentanil? Anesthesiology 78 : 486-491, 1993

7. Elder JB, Hoh DJ, Wang MY : Postoperative continuous paravertebral anesthetic infusion for pain control in lumbar spinal fusion surgery. Spine (Phila Pa 1976) 33 : 210-218, 2008

8. Fisher CG, Belanger L, Gofton EG, Umedaly HS, Noonan VK, Abramson C, et al. : Prospective randomized clinical trial comparing patient-controlled intravenous analgesia with patient-controlled epidural analgesia after lumbar spinal fusion. Spine (Phila Pa 1976) 28 : 739-743, 2003 
9. Geller E, Chrubasik J, Graf R, Chrubasik S, Schulte-Mönting J : A randomized double-blind comparison of epidural sufentanil versus intravenous sufentanil or epidural fentanyl analgesia after major abdominal surgery. Anesth Analg 76 : 1243-1250, 1993

10. Grieff AN, Ghobrial GM, Jallo J : Use of liposomal bupivacaine in the postoperative management of posterior spinal decompression. J Neurosurg Spine $25: 88-93,2016$

11. Jayr C, Beaussier M, Gustafsson U, Leteurnier Y, Nathan N, Plaud B, et al. : Continuous epidural infusion of ropivacaine for postoperative analgesia after major abdominal surgery : comparative study with i.v. PCA morphine. Br J Anaesth 81 : 887-892, 1998

12. Jeon HR, Chae WS, Lee SJ, Lee JH, Cho SH, Kim SH, et al. : A comparison of sufentanil and fentanyl for patient-controlled epidural analgesia in arthroplasty. Korean J Anesthesiol $60:$ 41-46, 2011

13. Lee SH, Kim KH, Cheong SM, Kim S, Kooh M, Chin DK : A comparison of the effect of epidural patient-controlled analgesia with intravenous patient-controlled analgesia on pain control after posterior lumbar instrumented fusion. J Korean Neurosurg Soc 50 : 205-208, 2011

14. Lötsch J : Pharmacokinetic-pharmacodynamic modeling of opioids. J Pain Symptom Manage 29(5 Suppl) : \$90-103, 2005

15. Lu S, Ma SC, Wang YY, Zhu ZH, Fan HW, Zhao GQ : Comparison of pain relief between patient-controlled epidural analgesia and patientcontrolled intravenous analgesia for patients undergoing spinal fusion surgeries. Arch Orthop Trauma Surg 135 : 1247-1255, 2015

16. Lutti MN, Vieira JL, Eickhoff DR, de Carli D, de Carvalho MA : Patient controlled analgesia with fentanyl or sufentanil in the postoperative period of knee ligament reconstruction: comparative study. Rev Bras
Anesthesiol 52 : 166-174, 2002

17. Maciejewski $D$ : Sufentanil in anaesthesiology and intensive therapy. Anaesthesiol Intensive Ther 44 : 35-41, 2012

18. Matsui H, Kanamori M, Terahata N, Miaki K, Makiyama N, Satone T, et al. : Significance of patient-controlled analgesia in combination with continuous epidural block for patients who underwent posterior lumbar surgery. Eur Spine J 7 : 120-124, 1998

19. Ong CK, Lirk P, Seymour RA, Jenkins BJ : The efficacy of preemptive analgesia for acute postoperative pain management : a meta-analysis. Anesth Analg $100: 757-773,2005$

20. Park SY, An HS, Lee SH, Suh SW, Kim JL, Yoon SJ : A prospective randomized comparative study of postoperative pain control using an epidural catheter in patients undergoing posterior lumbar interbody fusion. Eur Spine J 25 : 1601-1607, 2016

21. Schenk MR, Putzier M, Kügler B, Tohtz S, Voigt K, Schink T, et al. : Postoperative analgesia after major spine surgery : patient-controlled epidural analgesia versus patient-controlled intravenous analgesia. Anesth Analg 103 : 1311-1317, 2006

22. Teng YH, Hu JS, Tsai SK, Liew C, Lui PW : Efficacy and adverse effects of patient-controlled epidural or intravenous analgesia after major surgery. Chang Gung Med J 27 : 877-886, 2004

23. Wilhelm AJ, Dieleman HG : Epidural fentanyl and sufentanil for intraand postoperative analgesia. A randomized, double-blind comparison. Pharm World Sci 16 : 7-12, 1994

24. Wilhelm W, Kreuer $S$ : The place for short-acting opioids: special emphasis on remifentanil. Crit Care 12(Suppl 3) : S5, 2008 